\title{
TATA KELOLA TI MENGGUNAKAN COBIT 5 PADA SISTEM HELPDESK
}

\author{
IT Governance Using Cobit 5 \\ (A Case Study: Helpdesk System)
}

\author{
I Ketut Sudaryana ${ }^{1)}$, Ayudina Nur Afifah ${ }^{2)}$, Fitri Dwi Pussandha ${ }^{3)}$ \\ 1) Program Studi Teknik Informatika, STMIK Widuri, Jakarta \\ 2)Program Studi Sistem Informasi, FASILKOM, Universitas Mercu Buana, Jakarta \\ ${ }^{3)}$ Program Studi Sistem Informasi, FASILKOM, Universitas Mercu Buana, Jakarta
}

Diterima 1 Februari 2019 / Disetujui 25 Februari 2019

\begin{abstract}
Companies in the field of providing construction services and managing network infrastructure such as PT Telkom Akses cannot be separated from problems that exist in hardware, software, or because of human errors. This problem will also arise in the customer. The company handles these problems using a helpdesk system, namely the system used to send complaints from customers and from the company side (helpdesk) will provide a solution. With the helpdesk system, researchers conduct IT governance on the helpdesk system to find out the constraints of the processes that are already running, and know what needs to be developed from this system. The framework used for IT governance activities is Cobit 5 and focus on the EDMO2 domain. Before conducting IT governance, the author first made observations at PT Telkom Access to ensure the data obtained was valid and to ensure fulfillment of COBIT activities 5. Achievement of IT governance for the helpdesk system at PT Telkom Access on average at level 2,6.
\end{abstract}

Keywords: Helpdesk, IT Management, Systems, COBIT 5

\begin{abstract}
ABSTRAK
Perusahaan dalam bidang penyediaan layanan konstruksi dan pengelolaan infrastruktur jaringan seperti PT Telkom Akses tidak terlepas dari masalah yang ada pada hardware, software, atau karena kesalahan manusia. Permasalahan ini akan timbul juga pada customer. Perusahaan menangani masalah-masalah tersebut menggunakan sistem helpdesk, yaitu sistem yang digunakan untuk mengirimkan komplain dari customer dan dari sisi perusahaan (helpdesk) akan memberikan solusi. Dengan adanya sistem helpdesk, peneliti melakukan tata kelola TI terhadap sistem helpdesk untuk mengetahui kendala dari proses yang sudah berjalan, dan mengetahui apa saja yang perlu dikembangkan dari sistem ini. Framework yang digunakan untuk kegiatan tata kelola TI yaitu COBIT 5 dan focus pada domain EDM02. Sebelum melakukan tata kelola TI, penulis terlebih dahulu melakukan observasi di PT Telkom Akses untuk memastikan data yang telah didapat adalah valid serta untuk memastikan terpenuhinya aktivitas-aktivitas COBIT 5. Pencapaian tata kelola TI untuk sistem helpdesk di PT Telkom Akses rata-rata pada level 2,6.
\end{abstract}

Kata Kunci: Helpdesk, Tata Kelola TI, Sistem, COBIT 5

\section{PENDAHULUAN}

PT. Telkom Akses merupakan perusahaan yang bergerak dalam bisnis penyediaan layanan konstruksi dan pengelolaan infrastruktur jaringan. Layanan tersebut dilakukan oleh PT Telkom Akses

"Korespondensi Penulis:

E-mail: ketutsbali2010@gmail.com yang dikelompokkan menjadi proyek-proyek yang nantinya akan dikerjakan sesuai dengan lokasi dari proyek tersebut. Selama proyek dikerjakan, biasanya akan muncul kendala yang dialami oleh karyawan PT. Telkom Akses seperti teknisi yang akan memulai untuk survei lokasi sebelumnya harus mengambil alat kerja terlebih dahulu di gudang di lokasi dimana karyawan bekerja. Setelah teknisi mengambil alat kerja yang dibutuhkan, 
petugas gudang harus meng-input di aplikasi agar pemakaian alat kerja dapat tercatat dengan baik. Namun ada kendala saat pengisian di aplikasi tersebut. Karena ada kendala pada saat peng-input-an pemakaian alat kerja, maka teknisi juga mengalami kerugian waktu yang seharusnya sudah digunakan untuk survei ke lokasi, hal tersebut akan menghambat kinerja.

Chatra merupakan aplikasi chatting yang digunakan untuk pengaduan user kepada helpdesk IT PT. Telkom Akses. Aplikasi ini bertujuan untuk memudahkan user dalam melakukan pengaduan apabila sistem-sistem yang dipakai oleh user mengalami masalah (Telkom Akses, 2018).

Perusahaan pada umumnya selalu mempunyai tujuan-tujuan yang harus dicapai dalam mengedepankan nilai jual perusahaan. Oleh karena itu perusahaan yang sudah berjalan perlu diadakan tata kelola untuk mengetahui proses yang sudah berjalan dengan proses pembangunannya apakah terdapat kendala-kendala yang perlu diketahui oleh pimpinan perusahaan. Salah satu framework dapat digunakan sebagai acuan untuk melakukan tata kelola adalah COBIT 5 (Agung \& Andry, 2018). Oleh karena itu fokus penelitian ini menggunakan EDM02 yaitu Ensure Benefits Delivery untuk mengoptimalkan kontribusi nilai bisnis perusahaan. Tujuan dari proses ini adalah mengamankan nilai optimal dari IT berupa, layanan, dan asset dan penyampaian solusi yang dapat diandalkan dengan akurat sehingga kebutuhan bisnis didukung secara efektif dan efisien (Octaviyanti \& Andry, 2018).

\section{STUDI PUSTAKA}

\section{Help Desk}

Helpdesk berfungsi untuk mencatat dan mengklasifikasikan permasalahan yang terjadi serta solusinya, sehingga dapat dipergunakan dan menjadi aset knowledge bagi perusahaan. Helpdesk sebaiknya dibantu oleh perangkat lunak tertentu untuk memfasilitasi rekap data, monitoring kegiatan, dan pelaporan. "Helpdesk is a formal organization that provides support function to users of the companies product, services, or technology". Jadi helpdesk merupakan bagian dari perusahaan yang menyediakan dokumen fungsi produk, servis atau teknologi dari perusahaan tersebut (Wooten, 2001).

\section{COBIT 5}

COBIT merupakan kerangka kerja dan alat pendukung yang memungkinkan manajer menjembatani kesenjangan sehubungan dengan mengendalikan persyaratan, masalah teknis dan risiko bisnis, dan berkomunikasi tingkat kontrol kepada stakeholder (ITGI, 2007). COBIT memungkinkan pengembangan kebijakan yang jelas dan praktik yang baik untuk mengontrol TI di seluruh perusahaan. COBIT terus disesuaikan dan diselaraskan dengan standar dan pedoman lainnya. Oleh karena itu, COBIT telah menjadi integrator praktik tata kelola TI yang baik dan membantu dalam memahami, mengelola risiko serta manfaat yang terkait dengan TI (Andry, 2016).

\section{Level Kapabilitas}

Level kapabilitas proses yang digunakan di dalam penilaian proses terdiri dari enam level yaitu: (ISACA, 2012)

Level 0: Incomplete Process, yaitu proses tidak diimplementasi atau gagal mencapai tujuan proses. Terdapat sedikit atau tidak ada bukti pencapaian tujuan proses secara sistematis.

Level 1: Performed Process, yaitu implementasi proses mencapai tujuannya. Atribut proses yang mencerminkan pencapaian level minimum ini adalah PA1.1 Process Performance.

Level 2: Managed Process, yaitu proses pada level 1 diimplementasi ke dalam sebuah pengaturan proses (direncanakan, dimonitor, dan dievaluasi) dan produk kerja proses tersebut ditetapkan, dikontrol, dan dipertahankan secara tepat.

Level 3: Established Process, yaitu proses pada level 2 diimplementasi menggunakan 
proses yang terdefinisi dan mampu mencapai hasil proses.

Level 4: Predictable Process, yaitu proses pada level 3 dijalankan dengan batasan yang telahterdefinisi untuk mencapai hasil proses.

Level 5: Optimizing Process, yaitu proses pada level 4 ditingkatkan secara berkelanjutan untuk memenuhi tujuan organisasi saat ini dan saat mendatang (Christianto \& Andry, 2018).

\section{METODE PENELITIAN}

Dalam penelitian ini perumusan objek penelitian dilakukan setelah izin penelitian diterima dan berdasarkan hasil diskusi dengan pihak perusahaan. Peneliti mengajukan izin penelitian kepada Manager IT Operation PT. Telkom Akses, izin penelitian untuk tata kelola dengan judul "Tata Kelola TI Terhadap Sistem Helpdesk Menggunakan COBIT 5" dengan studi kasus PT Telkom Akses. Melalui hasil diskusi dengan pihak perusahaan, maka objek penelitian ini adalah PT. Telkom Akses.

Dalam melakukan penelitian ini, terdapat tahap-tahap yang dilakukan untuk mencapai keberhasilan dalam penulisan jurnal ini. Tahapan penelitian yang digunakan adalah dimulai dari studi kepustakaan sampai penyerahan laporan hasil tata kelola kepada perusahaan. Terdapat delapan tahap-tahap penelitian yang digunakan ditunjukkan pada Gambar 1. Tahapan Penelitian.

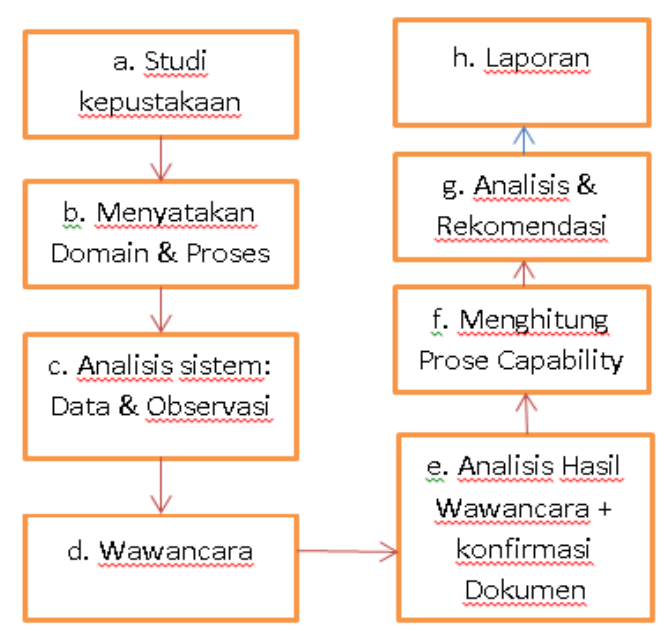

Gambar 1. Tahapan Penelitian (Elshaddai \& Andry, 2018).
Berikut merupakan penjelasan setiap tahapan pada metodologi penelitian:

a) Melakukan studi kepustakaan tentang tata kelola teknologi informasi, sistem,helpdesk, COBIT 5.

b) Menyatakan domain dan proses yang digunakan yaitu EDM02.

c) Mengumpulkan data yang berkaitan dengan aktivitas pada setiap proses EDM02. Melakukan observasi untuk memastikan data yang telah didapat adalah valid serta untuk memastikan terpenuhinya aktivitas-aktivitas.

d) Melakukan wawancara dengan pihakpihak yang bersangkutan, pada setiap pertanyaan wawancara adalah berdasarkan pada aktivitas pada proses EDM02.

e) Melakukan analisis terhadap hasil dari wawancara serta melakukan konfirmasi dokumen-dokumen yang didapat.

f) Menghitung setiap proses menggunakan capability model untuk mengetahui level kapabilitas perusahaan.

g) Memberikan rekomendasi dari hasil analisis.

h) Hasil dari penelitian ini berupa laporan yang akan diberikan kepada perusahaan.

Penulis melakukan analisis wawancara kepada 4 orang IT mengenai sistem tersebut serta memperoleh hasil dari analisis untuk mengoptimalkan kontribusi nilai bisnis dan keuntungan perusahaan dan memastikan optimalisasi sumber daya yang ada di dalam perusahaan. Sub-domain yang dibahas adalah EDM02 (Ensure Benefits Delivery).

\section{HASIL DAN PEMBAHASAN}

Pada bagian ini penulis akan membahas hasil dari audit sistem Helpdesk pada bagian maintenance menggunakan kerangka kerja COBIT 5.

\section{EDM02 (Ensure Benefits Delivery)}

EDM02 merupakan proses atau subdomain dari domain EDM (Evaluate, Direct and Monitor) yang berada dalam area tata 
kelola. Deskripsi dari proses atau sub-domain ini adalah mengoptimalkan kontribusi nilai pada bisnis dari proses bisnis, layanan TI dan aset TI dengan biaya yang dapat diterima. Tujuan dari proses ini adalah mengamankan nilai optimal dari inisiatif IT-enabled, layanan, dan aset. Penyampaian solusi dan layanan yang hemat biaya. Gambaran biaya dan manfaat yang dapat diandalkan dengan akurat sehingga kebutuhan bisnis didukung secara efektif dan efisien.

Proses ini memiliki tiga governance practice atau sub-proses, berikut merupakan tiga sub-proses pada EDM02:

1. EDM02.01 Evaluate Value Optimization.

2. EDM02.02 Direct Value Optimization.

3. EDM02.03 Monitor Value Optimization.

Terdapat aktivitas-aktivitas yang dilakukan untuk penilaian level kapabilitas pada bagian EDM02.01 sebagai berikut:

1. Memahami persyaratan stakeholder; isu strategis TI, seperti ketergantungan pada TI; dan wawasan dan kemampuan teknologi mengenai potensi aktual dan potensial TI untuk strategi perusahaan.

2. Memahami elemen kunci dari tata kelola yang diperlukan untuk penyampaian nilai optimal yang andal, aman dan hemat biaya dari penggunaan layanan, aset dan sumber daya TI yang ada dan yang baru.

3. Memahami dan secara teratur mendiskusikan peluang yang bisa timbul dari perubahan perusahaan yang dimungkinkan oleh teknologi terkini, baru atau yang baru muncul, dan mengoptimalkan nilai yang tercipta dari peluang tersebut.

4. Memahami apa yang merupakan nilai bagi perusahaan, dan mempertimbangkan seberapa baik komunikasi, dipahami dan diterapkan sepanjang proses perusahaan.

5. Mengevaluasi seberapa efektif strategi perusahaan dan TI telah terintegrasi dan selaras dalam perusahaan dan dengan tujuan perusahaan untuk memberikan nilai.

6. Memahami dan mempertimbangkan seberapa efektif peran, tanggung jawab, akuntabilitas, dan pengambilan keputusan saat ini dalam menjamin penciptaan nilai dari investasi IT-enabled, layanan dan aset.

7. Melakukan pertimbangan seberapa baik pengelolaan investasi, layanan dan aset yang diaktifkan TI sesuai dengan praktik manajemen nilai dan pengelolaan keuangan perusahaan.

8. Mengevaluasi portofolio investasi, layanan dan aset agar sesuai dengan tujuan strategis perusahaan; layak perusahaan, baik finansial maupun nonfinansial; risiko, risiko melahirkan dan risiko manfaat; keselarasan proses bisnis; efektivitas dalam hal kegunaan, ketersediaan dan daya tanggap; dan efisiensi dalam hal biaya, redundansi dan kesehatan teknis.

Berdasarkan hasil wawancara dan observasi yang telah dilakukan berdasarkan aktivitas-aktivitas COBIT 5 sub-proses EDM02.01, terdapat temuan tata kelola TI berdasarkan kondisi perusahaan saat ini, adalah sebagai berikut:

- Perusahaan memahami potensi dari perkembangan teknologi baru.

- Memahami kemampuan teknologi yang dimiliki untuk potensi strategi perusahaan.

- Terdapat pertimbangan dalam pengelolaan aset dengan keuangan.

- Adanya evaluasi terhadap strategi untuk meningkatkan nilai bisnis, terdapat tata kelola dan peluang untuk mengoptimalkan nilai binis.

- Berdasarkan hasil temuan tata kelola subproses EDM02.01 Evaluate Value Optimization, sub-proses ini memiliki pencapaian atribut level kapabilitas di Level 3 yaitu Established Process

Terdapat aktivitas-aktivitas yang dilakukan untuk penilaian level kapabilitas pada bagian EDM02.02 sebagai berikut:

- Menentukan dan mengkomunikasikan jenis portofolio, jenis investasi, kategori, kriteria dan bobot relatif terhadap kriteria 
untuk memungkinkan nilai-nilai relatif keseluruhan.

- Menentukan persyaratan untuk dan ulasan lainnya untuk kepentingan investasi bagi perusahaan dan risiko, jadwal program, rencana pendanaan, dan penyampaian kemampuan dan keuntungan utama serta kontribusi berkelanjutan terhadap nilai.

- Adanya manajemen langsung untuk mempertimbangkan potensi penggunaan TI yang inovatif yang memungkinkan perusahaan merespons peluang atau tantangan baru, melakukan bisnis baru, meningkatkan daya saing, atau memperbaiki proses.

- Mengarahkan setiap perubahan yang diperlukan dalam penugasan pertanggungjawaban dan tanggung jawab untuk melaksanakan portofolio investasi dan memberikan nilai dari proses dan layanan bisnis.

- Menentukan dan mengkomunikasikan tujuan pengiriman nilai tingkat perusahaan dan ukuran hasil untuk memungkinkan pemantauan yang efektif.

- Mengarahkan dan mengkomunikasikan tingkat akuntabilitas dan tanggung jawab perusahaan untuk memberikan portofolio investasi dan memberikan nilai dari proses bisnis dan layanan.

- Merekomendasikan pertimbangan inovasi potensial, perubahan organisasi atau peningkatan operasional yang dapat mendorong peningkatan nilai bagi perusahaan dari inisiatif IT-enabled.

- Berdasarkan hasil temuan tata kelola subproses EDM02.02 Direct value optimisation, sub-proses ini memiliki pencapaian atribut level kapabilitas di Level 2 yaitu Managed Process

Terdapat aktivitas-aktivitas yang dilakukan untuk penilaian level kapabilitas pada bagian EDM02.03 sebagai berikut:

- Menentukan seperangkat tujuan kerja, matrik, target, dan tolak ukur yang seimbang.

- Mengumpulkan data yang relevan, tepat waktu, lengkap, dapat dipercaya dan akurat untuk melaporkan kemajuan dalam memberikan nilai terhadap target.

- Mendapatkan laporan kinerja portofolio, program TI (teknologi dan fungsional) reguler dan relevan. Kemajuan yang telah dicapai perusahan menuju sasaran yang teridentifikasi dan sejauh mana tujuan yang telah direncanakan tercapai, diperoleh, target kinerja terpenuhi dan risiko bisa dimitigasi.

- Setelah meninjau laporan, management melakukan tindakan yang tepat sesuai kebutuhan untuk memastikan bahwa nilai Teknologi Informasi dioptimalkan.

- Setelah meninjau laporan, memastikan tindakan perbaikan manajemen yang tepat dimulai dan dikendalikan.

- Berdasarkan hasil temuan tata kelola subproses EDM02.03 Monitor value optimisation, sub-proses ini memiliki pencapaian atribut level kapabilitas di Level 3 yaitu Established Process.

\section{Analisis Level Kapabilitas pada Proses EDM02}

Berdasarkan hasil temuan tata kelola dapat diketahui pencapaian atribut proses untuk setiap sub-proses dalam proses EDM02. Perusahaan memiliki sistem manajemen mutu yang baik. Sub-proses EDM02.01 tercapai sepenuhnya, sub-proses EDM02.02 telah mencapai level kapabilitas 2. Sub-proses EDM02.03 mencapai level kapabilitas 3, bisa dilihat pada Tabel 1. Level Kapabilitas EDM02.

Tabel 1 Level Kapabilitas EDM02

\begin{tabular}{|c|c|}
\hline Governance Practice & Level Kapabilitas \\
\hline EDM02.01 & 3 \\
\hline EDM02.02 & 2 \\
\hline EDM02.03 & 3 \\
\hline Rata-rata & 2,6 \\
\hline
\end{tabular}

\section{Analisis Gap dan Rekomendasi}

Berdasarkan hasil analisis level kapabilitas yang menghasilkan rata-rata level kapabilitas setiap proses, kemudian dibandingkan expected level yang didapat. Gap berupa jarak dari rata-rata level kapabilitas 
dengan expected level. Expected Level merupakan level kapabilitas yang diharapkan adalah di atas satu level dari level kapabilitas saat ini. Analisis gap setiap proses ditunjukkan pada Tabel 2. Analisis Gap.

Tabel 2. Analisis Gap

\begin{tabular}{|l|l|l|l|}
\hline Proses & $\begin{array}{l}\text { Rata-rata } \\
\text { Level }\end{array}$ & $\begin{array}{l}\text { Expected } \\
\text { Level }\end{array}$ & GAP \\
\hline EDM02 & 2,6 & 3 & 0.4 \\
\hline
\end{tabular}

\section{Rekomendasi berdasarkan proses EDM02}

Untuk meningkatkan proses EDM02

Ensure Benefits Delivery agar dapat mencapai expected level dibutuhkan rekomendasi. Berikut merupakan rekomendasi untuk meningkatkan proses EDM02 yaitu agar lebih fokus kepada pembenahan dokumen-dokumen dan manajemen sistem-sistem yang ada di unit $I T$, lebih rutin untuk perawatan sistem dan aplikasi, bisnis proses lebih diperhatikan.

\section{SIMPULAN}

Berdasarkan hasil analisis penelitian ini, kesimpulan yang didapat adalah bahwa PT. Telkom Akses memiliki proses pemeliharaan tata kelola TI, optimasi nilai, tata kelola perubahan, manajemen risiko dan manajemen aset yang sudah sangat baik. Beberapa proses hampir memiliki standar yang dilaksanakan secara efektif. Pencapaian tata kelola TI di PT Telkom Akses rata-rata pada level 2,6 pada skala 5 .

\section{SARAN}

Saran yang diberikan setelah mendapat hasil penelitian adalah sebagai berikut:

PT Telkom Akses Unit IT diharapkan dapat melakukan implementasi perbaikan berdasarkan rekomendasi-rekomendasi yang telah diberikan. Diharapkan untuk melakukan tata kelola secara berkala setiap 6 bulan sekali. Kepada peneliti selanjutnya, diharapkan dapat menggunakan seluruh domain pada COBIT 5, tidak hanya terbatas pada domain EDM.

\section{DAFTAR PUSTAKA}

Andry, J. F. 2016. Audit of IT Governance Based on COBIT 5 Assessments: A Case Study. Jurnal Teknosi, Vol. 2, no. 2, pp 27-34.

Agung, H., \& Andry, J. F. 2018. Audit Sistem Informasi Akademik Menggunakan Kerangka Kerja Cobit 5 Pada Domain Edm Di Universitas XYZ. Journal of Business and Audit Information Systems Vol. 1, No.1, pp. 38 - 49.

Christianto, K., \& Andry, J. F. 2018. Audit Menggunakan Cobit 4.1 Dan Cobit 5 Dengan Case Study", Teknosain, Yogyakarta.

Elshaddai, S. B., \& Andry, J. F. 2018. Audit Sistem Informasi Inventory Menggunakan Kerangka Kerja COBIT 5 DI PT. Everlight. Vol. 2, No. 1, pp. $26-$ 33.

Octaviyanti, P., \& Andry, J. F. 2018. Audit Sistem Enterprise Asset Management Menggunakan Framework COBIT 5. Ikraith-Informatika, Vol. 2, No. 1, pp. 34 -42 .

Telkom Akses, "Aplikasi Chatra," [Online]. Diakses pada 08 November 2018.

ISACA: COBIT Five: A Business Framework for the Governance and Management of Enterprise IT, 2012.

ITGI: COBIT Mapping: Mapping ISO/IEC 17799:2005 with COBIT 4.0, p. 6.

ITGI: COBIT 4.1 Excerpt, p. 9, 2007.

Wooten, G. W. 2001. Building \& Managing a World Class IT Help Desk. MCGrawHill. 